\title{
The effects of habenular and medial forebrain bundle lesions on sexual behavior in female rats'
}

\author{
CHARLES H. ROOGERS?', DEPARTMENT OF PHYSIOLOGY, STANFORD UNIVERSITY \\ 0. THOMAS LAW, DEPARTMENT OF PSYCHOLOGY, CLAREMONT GRADUATE SCHOOL
}

A comparison was made of the effects of habenular and medial forebrain bundle lesions on female rat sexual behavior as measured by the lordosis-to-mount ratio, and by the female's avoidance of sexual contact. Results show that destruction of the habenulae causes a decreased lordosis response, and a greater avoidance of male sexual contacts. Medial forebrain bundle lesions had a less pronounced effect on the female's behavior.

Few studies have reported the effects of subcortical destruction on copulatory behavior in the female rat. It is accepted that circumscribed destruction of the anterior hypothalamus causes female rats to become anovulatory and behaviorally nonreceptive (Flerko, 1963). In 1958, Law \& Meagher noted that female rats refuse to mate subsequent to anterior hypothalamic destruction even when in a state of vaginal estrus. In addition, bilateral destruction of the medial habenulae has been reported to cause "frequent" mating in female rats during vaginal diestrus, while destruction of lateral habenulae is without effect (deGroot, 1962). No behavioral quantification is reported in these studies.

Except for the few investigations on the anterior hypothalamus, habenula, and amygdala (see Goddard, 1964) there is little evidence on the effects of destroying other components of the limbic system on female rat sexuality. The medial forebrain bundle, which has been implicated in the ejaculatory pattern (Herberg, 1963; MacLean et al, 1961) has not been studied in connection with copulatory behavior in the female rat.

The purpose of this study is to explore and evaluate in more detail female rat sexual behavior subsequent to lesions in the habenula and medial forebrain bundle.

In this study, female rat sexual behavior is determined by the lordosis-to-mount ratio (Kuehn \& Beach, 1962), and by a method which provides a measure of self-paced avoidance by the female of contact with sexually vigorous males (Bermant, 1961; Pierce \& Nuttall, 1961).

Method

The Ss were 13 90-day-old, sexually naive, hooded female rats. All Ss were ovariectomized, and 10 days later sexual receptivity was induced by administration of $500 \mu \mathrm{g}$ diethylstilbestrol (s.c.) followed $40 \mathrm{hr}$. later by $1 \mathrm{mg}$ of progesterone. Six hr. after the progesterone injection, $S$ s received a $15 \mathrm{~min}$. behavioral test (experiencing trial). The injection-trial sequence was repeated three times at one week intervals. Two weeks subsequent to the experiencing trials, the preoperative tests were initiated. Each S received one $15 \mathrm{~min}$. trial while nonreceptive and one $15 \mathrm{~min}$. trial while receptive. Receptivity was induced as described above.

Lesions were produced by monopolar stainless steel electrodes, insulated except for $.008 \mathrm{in}$. at the tip, under the following conditions: (1) Habenula (Hab)-2 $\mathrm{mA}$ anodal current for 10 sec.; (2) Medial forebrain bundle (MFB) $-2 \mathrm{~mA}$ anodal current for $15 \mathrm{sec}$. Coordinates for the target areas were obtained from deGroot (1959).

Copulatory tests were conducted in a cylindrical mating arena made of clear Plexiglas 18 in. high $\mathbf{x}$ 20 in. in diameter, supported on a table surfaced with 1/2-in. hardware cloth. A mirror, fixed at an angle beneath the table, allowed simultaneous observation of the arena floor. Three to five males occupied the arena floor during testing.

To obtain a measure of the initiation or termination of sexual contact by the females, an escape stand was mounted in the center of the arena floor. The stand measured 5 in. square $\times 6$ in. in height. The stand top depressed when occupied by a female rat, activating a microswitch and deflecting a pen on an event recorder. In addition to this record of amount of time spent on the stand (Ts) and the frequency of such contacts (Fs), E recorded with separate switches the frequency of mounts, intromissions, ejaculations, and lordoses.

Prior to the experiment, the Ss were housed in adaptation cages with escape stands similar to that used in the testing arena. Males were preselected for mating

Table 1. Median scores and ranges for each group for time on stand (Ts), frequency of stand contacts (Fs), and lordoses-to-mounts ratio $(L / M)$ for each condition under preoperative and postoperative testing.

\begin{tabular}{lrrrrrr} 
& \multicolumn{3}{c}{ Preoperative } & \multicolumn{3}{c}{ Postoperative } \\
Hab(n-7) & \multicolumn{1}{c}{ Mdn Ts } & Mdn Fs & Mdn L/M & Mdn Ts & Mdn Fs & Mdn L/M \\
\cline { 2 - 6 } Estrus & .21 & 3 & .94 & .96 & 9 & .66 \\
Range & $.03-.58$ & $0-17$ & $.90-1.00$ & $.15-4.84$ & $1-31$ & $.47-.91$ \\
Diestrus & 1.64 & 7 & .00 & 2.28 & 19 & .00 \\
Range & $.04-4.00$ & $4-17$ & .00 & $1.05-4.28$ & $8-40$ & .00
\end{tabular}

$\operatorname{MFB}(n-6)$

\begin{tabular}{lrrrrrr} 
Estrus & .27 & 4 & .99 & .53 & 3.5 & .93 \\
Range & $.07-.89$ & $0-22$ & $.96-1.00$ & $.08-10.48$ & $0-24$ & $.50-1.00$ \\
Diestrus & 1.87 & 8 & .00 & 2.62 & 17.5 & .00 \\
Range & $1.06-4.35$ & $4-20$ & .00 & $2.11-5.57$ & $2-25$ & .00 \\
\hline
\end{tabular}


vigor and housed next to the females in arena-like cages with no dummy escape stands. Thus, the female Ss but not the males were habituated to the escape stands. During testing, males seldom jumped on the escape stand. Any male attempting to follow the female onto the stand was tapped on the nose.

Prior to data analysis, lesion placements were verifled by studying frozen sections of the brain cut at $40 \mu$ and stained with Toluidine Blue.

\section{Results}

As indicated in Table 1, females spend more time on the escape stand (Ts) during diestrus than during estrus ( $p<.001$, Sign test). Analysis of the frequency of jumping onto the stand (Fs) reveals that Ss jump more often during diestrus than during estrus ( $p<.001$, Chi square). Differences in the lordosis-to-mount ratio (L/M) corresponding to estrus (.99 for $\mathrm{MFB}$ and .94 for $\mathrm{Hab}$ ) and diestrus $(.0$ and .0 ) were not treated statistically in view of the obvious differences.

A comparison of behavioral responses in the two lesion groups shows that females with Hab lesions manifest fewer lordoses (.66 vs. .93) than those with MFB destruction ( $p<.05$, Mann-Whitney). However, Ss in the Hab group show postoperative increases in frequency of jumps onto the stand during estrus and diestrus ( $p<.01$, Chi square), whereas $S s$ in the MFB group show increases in postoperative stand contacts only during diestrus (8.0 to 17.5$)$.

\section{Discussion}

The results show that $T s$ is a valid measure of sexual behavior in the female rat. The lordosis-to-mount ratio is directly proportional to receptivity, while $T s$ is inversely proportional to it.

Postoperative decreases in the frequency of lordoses may be viewed as indicating a reduced ability to copulate because of motor damage. If lesions resulted in motor debilitation, then Fs would have decreased with $L / M$, resulting in increased time spent in the arena. The Fs and Ts data, however, do not suggest a loss of motor function, as Fs increased, as did Ts, during postoperative estrus and diestrus trials. Since $L / M$ and $\mathrm{Fs}$ are, in this instance, affected differently, it is likely that there was no motor debilitation caused by lesioning.

It is clear that Ss differed in the lordosis response depending upon lesion placement. The difference in $\mathrm{L} / \mathrm{M}$ is independent of the amount of tissue destruction, as the Hab lesions were smaller than the MFB lesions (20 vs. $30 \mathrm{C}$ ), yet they reduced L/M to a greater extent. Presumably the $L / M$ differences reflect functional properties peculiar to the Hab areas, such as: (1) The animal is unable to inhibit behavior inappropriate to the mating situation, suggesting a motor inhibitory role as proposed by Herrick (1948); (2) Information from various subcortical systems is not processed and relayed to the effector reglons, suggesting a breakdown in integrative function (Prosser, 1961); or (3) The animal is in a generalized state of arousal such that stimuli are reacted to as if aversive.

Medial forebrain bundle destruction had little effect on the female once she was mounted by the male. However, these data suggest that females sustaining MFB damage show more avoidance during diestrus, and less avoidance during estrus than those with Hab destruction. One might speculate that MFB ablation caused an increased sensitivity to aversive stimuli-i.e., when not receptive, the males attempting to mount the females may be construed as aversive. On the other hand, the differences in $\mathrm{Ts}$ between the groups appear to be only relative, as both groups avoided the males more subsequent to surgery than before surgery.

The Hab regions are apparently related to female rat sexual behavior, whereas the MFB regions do not appear to be so related. Although both groups were less receptive during postoperative trials, the Ts and Fs measures suggest that Ss with fewer lordoses actively avoided the males and not that they lost the ability to respond with a lordosis. Thus, the additional information supplied by the time on stand and frequency of jumps to the stand allows one to distinguish decreased ability to copulate from avoldance of copulation.

\section{References}

Bermant, G. Response latencies of female rats during sexual intercourse. Science, 1961, 133, 1771-1773.

deGroot, J. The rat forebrain in stereotaxic coordinates. Verb. Kon. Ned. Akad. Wet., B. Natuurkunde, 1959, 52, 1-40.

deGroot, J. The influence of 'Iimbic' brain structures on reproductive functions in female rats. Excerpta Medica, 1962, \#48.

Flerko, B. The central nervous system and the secretion and release of luteinizing hormone and follicle stimulating hormone. In A. V. Nalbandov (Ed.), Advances in neuroendocrinology, Urbana: University of Illinois, 1963. Pp. 211-224.

Goddard, G. V. Functions of the amygdala. Psychol. Bull., 1964, $62,89-109$.

Herberg, L. H. Seminal ejaculation following positively reinforcing electrical stimulation of the rat hypothalamus. J. comp. physiol. Psychol., 1963, 56, 679-685.

Herrick, J. C. The habenula and its connections. In The brain of the tiger salamander. Chicago: University of Chicago, 1948. Pp. 247-264.

Kuehn, R. E., \& Beach, F. A. Quantitative measurement of sexual receptivity in female rats. Behav., 1962, 21, 282-299.

Law, O. T., \& Meagher, W. Hypothalamic lesions and sexual behavior in the female rat. Science, 1958, 128, 1626-1627.

Maclean, P. D., Denniston, R. H., Dua, S., \& Ploog, D. W. Physiologie de l'hippocampe. Intern. Colloq. Nat'l. Cent. Scient. Res., 1961, 107, 492-510.

Papez, J. W. Comparative neurology. New York: Hafner, 1929. P. 300.

Peirce, J. T., \& Nuttal, R. L. Self-paced sexual behavior in the female rat. J. comp. physiol. Psychol., 1961, 54, $310-313$.

Prosser, C. L. Nervous systems. In C. L. Prosser \& F. A. Brown (Eds.), Comparative animal physiologv. Phlladelphia: Saunders, 1961. Pp. 587-661.

\section{Notes}

1. Supported in part by USPHS Grant HD 00343-0352 to O. T. Law. 2. Completed while USPHS Predoctoral Fellow. Gratitude is expressed to Julian M. Davidson, Stanford University, for his assistance. 